\title{
INSTALLATION FOR MEASURING THE ELECTRIC PROPERTIES OF SOIL WITH A LINEAR MOTOR
}

Key words: conductivity; soil electrical resistivity; electrical current; remote soil monitoring; digital technology; agricultural land; soils.

\section{Authors' personal details}

1. Marat Tuktarov, Candidate of Technical Sciences, Associate Professor of the Department of Electrical Machines and Electrical Equipment, Federal State Budgetary Educational Institution of Higher Education «Bashkir State Agrarian University», 450001, Ufa, 50-letiya Oktiabrya Str., 34, e-mail: Marat.TukZar@yandex.ru.

2. Salavat Akchirin, Candidate of Technical Sciences, Associate Professor of the Department of Electrical Machines and Electrical Equipment, Federal State Budgetary Educational Institution of Higher Education «Bashkir State Agrarian University», 450001, Ufa, 50-letiya Oktiabrya Str., 34, e-mail: akchurin.sw@yandex.ru.

3. Svetlana Fefelova, Post-graduate student of the Department of Electrical Machines and Electrical Equipment, Federal State Budgetary Educational Institution of Higher Education «Bashkir State Agrarian University», 450001, Ufa, 50-letiya Oktiabrya Str., 34, e-mail: www.Svet1k15@mail.ru.

4. Bulat Khalilov, Candidate of Technical Sciences, senior Lecturer, Department of Power Supply and Process Automation, Federal State Budgetary Educational Institution of Higher Education «Bashkir State Agrarian University», 450001, Ufa, 50-letiya Oktiabrya Str., 34, e-mail: 79373565758@mail.ru.

The article proposes a method and device for studying the soil's electrical conductivity to quickly and easily determine the characteristics that allow a qualitative assessment of soil fertility (salinity, humus content, soil $\mathrm{pH}$, etc.). The proposed soil monitoring device based on an unmanned electric unit automatically follows a predetermined course ac- cording to GPS/GLONASS navigation systems' signals, which will automate soil research with simultaneous coordination of research sites. The creation of a soil monitoring system will speed up soil research and processing of results for accurate and timely adoption of measures to increase or maintain the fertility of agricultural land.

(C) Фефелова С.В., Туктаров М.Ф., Акчурин С.В., Халилов Б.Р.

УДК 631.3

DOI: $10.31563 / 1684-7628-2020-56-4-136-144$

Э.Р. Хасанов, Х.Т. Каримов, Д.И. Маскулов

\section{ТЕОРЕТИЧЕСКИЕ ИССЛЕДОВАНИЯ СКАРИФИКАЦИИ СЕМЯН КОЗЛЯТНИКА ЭКСПЕРИМЕНТАЛЬНЫМ СКАРИФИКАТОРОМ}

\author{
Ключевые слова: скарификация; скарификатор семян; вращающийся диск; частица; скорость \\ удара; скорость схода; угол отражсния; абразив.
}

Введение. К предпосевной обработке семян козлятника восточного относятся способы: химический, биологический, скарификация.

Химический способ предпосевной подготовки семян (рисунок 1) основан на использовании химических соединений, токсичных для вредных организмов, с целью ограничения их численности [1]. Он заключается в протравливании, то есть обработке семян протравителями с целью уничтожения или подавления наружной и внутренней инфекции, а также создании защитного барьера от поражения их почвообитающими возбудителями болезней и вредителями в период прорастания. Основным недостатком химических препаратов является то, что они действуют не только на те объекты, против которых их используют, но и на различные виды полезных организмов, а также на человека.

В связи с этим все большее внимание уделяется биологическому способу предпосевной подготовки семян (рисунок 1) вследствие экологической безопасности биологических препаратов для человека, окружающей экосистемы и сельскохозяйственных животных [2]. Под биологическим методом понимается применение микроорганизмов, способствующих уничтожению болезней и вредителей. Однако количественному росту применения биопрепаратов препятствует отсутствие серийных машин, пригодных для обработки микроорганизмами [3]. Особое значение биологический метод имеет для козлятника восточного. Нормальное образо- 
вание на корнях клубеньков и лучшее развитие растений происходит в случае инокуляции перед посевом семян ризоторфином, который представляет собой препарат чистых культур клубеньковых бактерий. При этом одновременное протравливание семян химическими препаратами против вредителей и болезней недопустимо, поскольку отмечается гибель клубеньковых бактерий [4].

Одной из проблем при возделывании сельскохозяйственной культуры козлятник восточный является твердая и герметичная оболочка семян, в отдельных случаях до 80 \%, что приводит к неравномерным всходам и снижению урожайности [5]. Нарушение герметичности оболочки семян в процессе предпосевной подготовки называют скарификацией (рисунок 1), а устройства, применяемые для данного процесса, - скарификаторами семян [6].

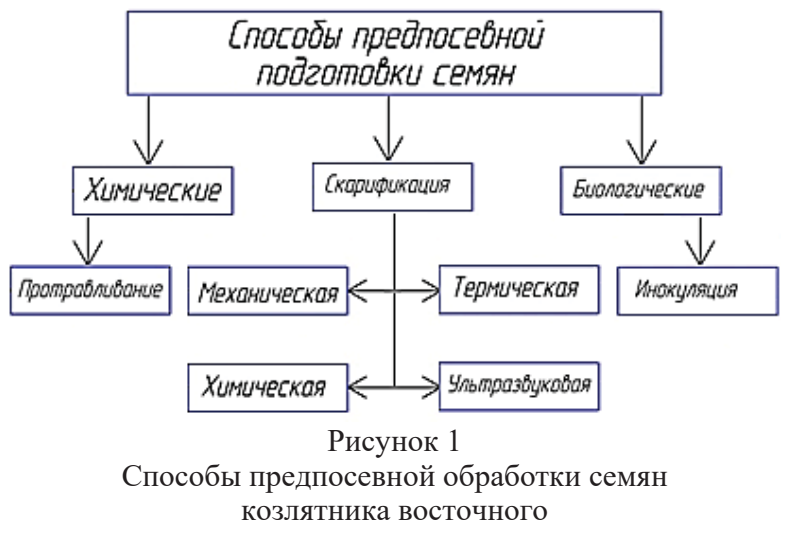

Существует несколько способов скарификации: механическая (физическое воздействие); химическая (обработка кислотой); термическая (прогревание и промораживание), ультразвуковая (рисунок 1). В России и за рубежом существуют различные точки зрения на эффективность и преимущества того или иного способа скарификации. На наш взгляд, химическая, термическая и ультразвуковая скарификации семян при всех своих достоинствах достаточно эффективна в лабораторных методах исследований, а также при обработке мелких партий семян [7]. На производстве основным, массовым способом скарификации является механическая. Применяемые при этом скарификаторы на рабочем диске придают семенам ускорение, вследствие чего те, срываясь с кромки диска, ударяются о абразивный круг, получая за счет контакта нарушение плотной герметичной оболочки, то есть скарифицируются. При этом имеющиеся конструкции несовершенны и обладают рядом недостатков: невысокое качество скарификации; повторные удары у части семян по скарифицирующей поверхности и соответственно их повышенная травмируемость $[8,9]$.
Кроме того, на производстве применяемая технология предпосевной обработки семян козлятника состоит из нескольких, выполняемых часто вручную, отдельных операций: скарификация семян; очистка скарифицированных семян от образовавшейся при обработке пыли и примесей от абразивной поверхности шлифовального круга; обработка очищенных семян на брезенте микробиологическим препаратом [10].

Цели и задачи исследования: предложить технологию и техническое решение, обеспечивающее повышение качества скарификации и последовательно выполняющее три механизированные операции: скарификацию, очистку семян и обработку их микробиологическим препаратом, а также произвести теоретические исследования технологического процесса скарификации семян методами классической механики и современными пакетами прикладных компьютерных программ.

Условия, материалы и методы исследований. Исходя из анализа существующих конструкций и теоретических исследований нами выдвинуто предположение, что повышение качества скарификации семян возможно путем совмещения в одном устройстве последовательной скарификации и инокуляции, при этом необходимо предусмотреть возможность регулирования угла касания семян с абразивной поверхностью при условии уменьшения степени травмированности и дробления семян [7, 10]. С учетом этого предлагается следующая схема обработки семян бобовых кормовых культур, согласно которой предусматриваются три последовательные зоны в камере обработки, одна из которых - зона скарификации, вторая - зона очистки семян от пыли и примесей, третья - зона обработки семян биологическим препаратом (рисунок 2).

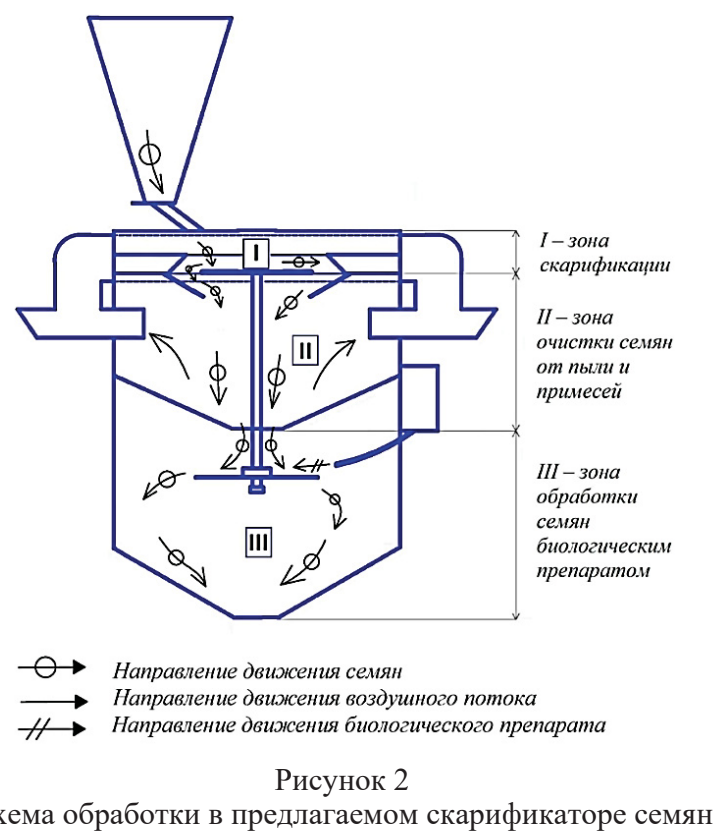


Первая операция - скарификация - проводится в I зоне. Семена козлятника загружаются в бункер, и включается привод. Дозирующим устройством устанавливают подачу семян на вращающийся диск с лопастями, которые изменяют направление движения семян, при этом возрастает их скорость. Сходя с диска, семена соприкасаются c абразивной поверхностью шлифовального круга, тем самым подвергаются скарификации путем нанесения царапин на твердую оболочку и создания возможности проникновения к зародышам влаги и воздуха. Вторая операция - очистка скарифицированных семян - проводится во II зоне. Скарифицированные семена после взаимодействия с абразивной поверхностью шлифовального круга сходят по конусной направляющей в камеру очистки, где через воздуховоды образовавшаяся пыль и примеси захватываются воздушным потоком, образованным вентилятором, и уходят за пределы установки. Третья операция - обработка скарифицированных, очищенных семян ризоторфином - проводится в III зоне. Биологический препарат из бака поступает в распылители, которые образуют аэрозоль. Семена направляются конусной поверхностью на нижкий диск, где за счет вращения и обработки аэрозолем покрываются каплями. После этого обработанные семена поступают в мешки через выходное окно.

Для определения качества обработки скарификации (степени скарификации и степени дробления) необходимо определить конструктивно-технологические параметры движения семени по диску и касания его с абразивной поверхностью шлифовального круга (зона 1).

В зоне скарификации на характер движения семян по диску прежде всего влияют конструктивные и технологические параметры дозатора: секундная подача семян на диск $Q$, площадь дозирующего окна, скорость поступления семян на диск $v$ и др. Кроме того, на характер движения семян будут влиять масса семян $m$, количество лопаток на диске $n_{l}$, частота вращения диска $n$, коэффициенты трения семян о лопатку и диск и т. д. Выходными данными являются время движения частиц семян по диску $t_{c}$, угол и скорость схода семян с диска $[6,11]$. При соприкосновении семян с абразивной поверхностью на процесс скарификации влияют такие параметры, как угол соприкосновения семян с поверхностью $\varphi$, угол отражения $\alpha$ семян от поверхности, скорость семян до соприкосновения с поверхностью $v_{c е м}$, угол трения $\varphi_{\text {T }}$ семени о поверхность, масса семян $m$, коэффициент восстановления скорости семени после удара $k$, зернистость абразивной поверхности $z$, мкм. Выходными показателями являются показатели качества обработки - степень скарификации $C$ и степень дробления семян $d, \%$ [12].
Выполнить поставленные цели и задачи по определению конструктивно-технологических параметров движения семени по диску и касания его с абразивной поверхностью шлифовального круга возможно методами классической механики и современными пакетами прикладных компьютерных программ.

Производительность экспериментального скарификатора семян $Q_{\Pi}$ составляет 300 кг/час, диаметр диска $D_{d}=240$ мм, минимальное $\left(n_{\min }=\right.$ 94,25 рад·c) и максимальное $\left(n_{\max }=261,79\right.$ рад $\cdot$ c $)$ число оборотов.

Величина секундной подачи семян на диск зависит от площади выгрузного окна дозатора, плотности семян и скорости поступления на диск:

$$
Q=F \cdot v \cdot \rho_{c},
$$

где $F$ - площадь выгрузного окна дозатора, ${ }^{2} ; v$ - скорость поступления, м/с; $\rho_{c}$ - плотность семян, кг $/ \mathrm{M}^{3}$.

От выгрузного окна дозатора семена подаются на диск через направитель в виде наклонной трубы. Рассмотрим движение семени в виде отдельной частицы по неподвижной трубе при угле ее наклона $\alpha_{\text {н }}$, большем угла трения $\varphi_{\text {T. }}$ На частицу массой $m$ действуют сила тяжести $m g$, сила трения $F$ и сила нормального давления $N$.

Дифференциальное уравнение движения частицы после простых преобразований приводится к виду [13]:

$$
\frac{d^{2} S}{d t^{2}}=\mathrm{g} \frac{\sin \left(\alpha_{\mathrm{H}}-\varphi_{\mathrm{T}}\right)}{\cos \varphi_{\mathrm{T}}}
$$

где $S$ - путь, пройденный частицей, м; $\varphi_{\text {т }}-$ угол трения частицы по материалу направителя; $\alpha_{\text {т }}$ угол наклона направителя к горизонту, град.; $g$ ускорение свободного падения, м/ $\mathrm{c}^{2}$.

При нулевых начальных условиях скорость $v$ схода частицы с направителя длиной $L$ определяется уравнением

$$
v=\sqrt{\frac{2 \mathrm{gL} \sin (\alpha-\varphi)}{\cos \varphi}} .
$$

Скорость $v$ является скоростью поступления семян на диск. От нее зависит место подачи и направление схода семян с диска.

Для определения характера движения семян по диску и скорости схода необходимо выбрать координаты места подачи семян на диск [14]. Выбор соответствующего места подачи на центробежный рабочий орган позволяет наряду с изменением количества оборотов определить и регулировать скорость схода семян с него [13]. Кроме того, как указывает Симонов М.В. [15], существенное влияние на показатели качества скарификации семян оказывают три фактора: частота вращения, подача исходного материала и зернистость скарифицирующей поверхности, в то же время изменение зазора между диском и абразивной поверхностью на изучаемые показатели качества оказывает несущественное влияние. 
Рассмотрим движение семян по лопатке горизонтального вращающегося диска (рисунок 3) с целью нахождения скорости и направления полета частицы после схода с диска. Для этого используем подходы и методы, предложенные В.А. Черноволовым в отношении моделирования процессов распределения минеральных удобрений центробежными дисками, но с учетом физико-механических свойств семян козлятника и конструкции экспериментального скарификатора семян [13].

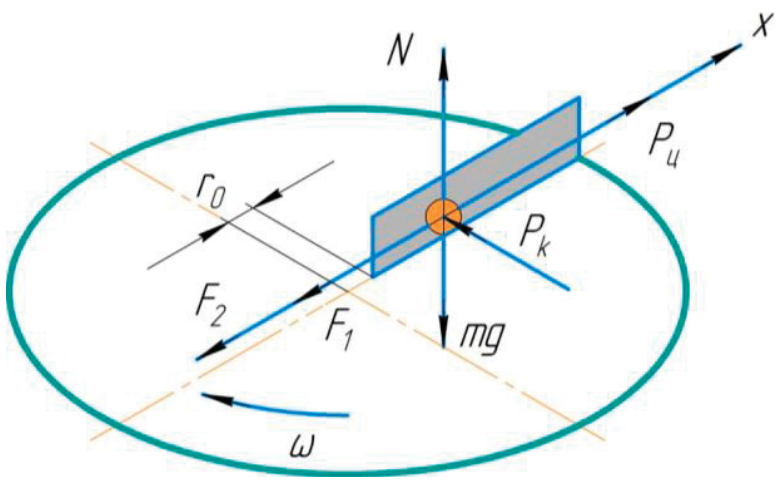

Рисунок 3

Силы, действующие на частицу, движущуюся по лопатке

На частицу массой $m$, захваченную лопаткой, в горизонтальной плоскости действуют центробежная сила инерции $P_{ц}=m r \omega^{2}$, нормальная реакция $N$, сила трения семени о поверхность диска $F_{1}=f_{1} m g$, сила трения семени о поверхность лопатки $F_{2}=2 f_{2} m \omega x^{I}$, сила Кориолиса $P_{k}=2 m \omega x^{I}$.

Дифференциальное уравнение движения частицы имеет вид

$$
x^{I I}=r \omega^{2}-f_{1} g-2 f_{2} \omega x^{I},
$$

где $f_{1}$ - коэффициент трения частицы о диск; $f_{2}$ - коэффициент трения частицы о лопатку; $x$ - ось координат, направленная вдоль лопатки; $r$ - радиус-вектор частицы; $r_{o}$ - радиус подачи частицы на лопатку.

Так как $r=r_{o}+x$, то уравнение (4) запишем в виде

$$
x^{I I}+2 f_{2} \omega x^{I}-\omega^{2} x=r_{0} \omega^{2}-f_{1} g .
$$

Уравнение левой части уравнения (2.5) имеет два решения

$$
\begin{gathered}
\lambda^{2}+2 f_{2} \omega \lambda-\omega^{2}=0 ; \\
\lambda_{1}=\frac{1-\sin \varphi}{\cos \varphi} \omega ; \\
\lambda_{2}=\frac{1+\sin \varphi}{\cos \varphi} \omega .
\end{gathered}
$$

Частное решение (5) при $x^{I}=0$ и $x^{I I}=$ 0 имеет вид

$$
x=-r_{0}+\frac{f_{1} g}{\omega^{2}} .
$$

Обозначим через $\mathrm{A}=\frac{f_{1} g}{\omega^{2}}, B=r_{0}$, тогда $x=$ $A-B$.

Общее решение уравнения

$$
x=\mathrm{C}_{1} e^{\lambda_{1} \cdot t}+\mathrm{C}_{1} e^{\lambda_{1} \cdot t}-\mathrm{B}+A .
$$

Постоянные интегрирования найдем при $t=$ $0 ; x^{I}=0$ и $x=0$

$$
\begin{gathered}
C_{1}=\frac{(B-A) \lambda_{2}}{\lambda_{2}-\lambda_{1}}, \\
C_{2}=-\frac{(B-A) \lambda_{1}}{\lambda_{2}-\lambda_{1}} .
\end{gathered}
$$

Тогда общее решение имеет вид

$$
x=(B-A)\left(\frac{1}{\lambda_{2}-\lambda_{1}}\left(\lambda_{2} e^{\lambda_{1} t}-\lambda_{1} e^{\lambda_{2} t}\right)-1\right) .
$$

Время движения частицы $t$ по лопатке найдем из уравнения (13), подставив в него полный путь движения частицы по лопатке, то есть

$$
x=R-r,
$$

где $R$ - радиус диска, м.

Так как время входит в показатели двух экспонент, то уравнение является трансцендентным относительно $t$. Решение его выполнено в системе Mathcad.

Относительную скорость движения частицы по лопатке определим по уравнению 14 .

$$
x^{I}=V_{r}=(B-A) \frac{\lambda_{1} \lambda_{2}}{\lambda_{2}-\lambda_{1}}\left(e^{\lambda_{1} t}-e^{\lambda_{2} t}\right) .
$$

Абсолютная скорость частицы в момент схода с диска находится суммированием векторов скоростей относительной $v_{r}$ и переносной $v_{e}$. Так как угол между ними прямой, то

$$
v_{a}=\sqrt{v_{r}+v_{e}} .
$$

Угол схода частицы, т. е. угловое перемещение частицы в абсолютном движении до момента схода с диска (рисунок 3 ) находится по формуле $\omega t_{1}$.

Тогда угол схода диска

$$
\alpha=\gamma+\omega \cdot t_{1}+\sigma-\pi+v_{g}
$$

где $\gamma$ - угловая координата точки подачи частицы; $\sigma$ - угол между абсолютной скоростью и радиус-вектором частицы; $v_{g}$ - скорость воздушного потока, образованного вентилятором системы очистки, м/с.

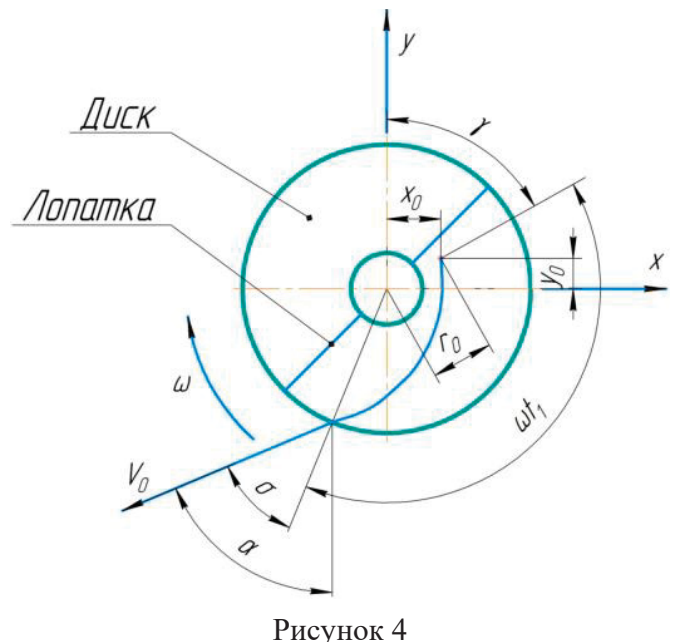

Определение кинематических параметров частицы при сходе с диска

После схода семян с диска и полета через зазор семена ударяются о шлифовальный круг. При изучении процесса скарификации следует 
рассмотреть взаимодействие пассивного рабочего органа в виде абразивного шлифовального круга и семян в виде активной частицы правильной шарообразной формы, поверхность шлифовального круга принять в виде плоскости и удар считать упругим.

Рассматривая взаимодействие частицы с шлифовальным кругом при ударе, когда масса круга существенно больше массы частицы, определяем, что скорость частицы после отскока после прямого центрального удара с поверхностью при условиях отсутствия трения и угла трения семени о поверхность $\varphi=o$ равна

$$
v_{\text {отс. }}=k \cdot V_{\text {отн. }}
$$

где $v_{\text {отс. }}-$ скорость частицы после отскока, м/с; $V_{\text {отн. }}-$ модуль скорости частицы относительно поверхности, м/с; $k$ - коэффициент восстановления скорости семени после удара.

Но прямой удар семян об абразивную поверхность шлифовального круга ведет к их чрезмерному дроблению, что является отрицательным фактором. Кроме того, в производственных условиях при скарификации семенного материала происходит изнашивание абразивной поверхности (выбивание абразивных частиц) по некоторой закономерности (дуга окружности или угол $45^{\circ}$ ), поэтому в большинстве случаев направление удара отклонено от нормали.

Рассмотрим случай удара частицы об абразивный круг под углом поверхности $45^{\circ}$ при следующих допущениях: частица движется одиночно, имеет форму шара (рисунок 5), а воздушный поток системы очистки постоянен по величине, скорости и направлению.

Скорость частицы $\vec{V}$ образует с нормалью к поверхности угол падения $\delta$. Необходимо определить скорость $\vec{u}$, с которой он отскакивает от этой поверхности. Для этого проводим через нормаль к поверхности и вектор скорости цен- тра частицы $\vec{V}$ плоскость, совместив ее с плоскостью. Спроецируем вектор скорости $\vec{V}$ на нормаль и касательную в этой плоскости. При допущении отсутствия трения реакция поверхности направлена по нормали и ее проекция на касательную $A \tau$ равна нулю. На основании теоремы о проекции количества движения

$$
m u_{\tau}-m V_{\tau}=0 \text { или } u_{\tau}=V_{\tau} \text {. }
$$

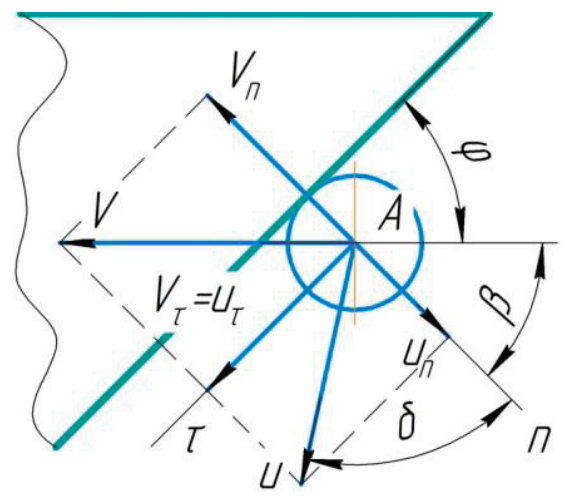

Рисунок 5

Соприкосновение частицы с абразивной поверхностью

Так как процесс скарификации сопровождается стиранием поверхности семени об абразивную поверхность, то уравнение 18 принимает вид:

$$
m u_{\tau} f_{3}-m V_{\tau}=0 \text { или } u_{\tau} f_{3}=V_{\tau},
$$

где $f_{3}$ - коэффициент трения частицы об абразивную поверхность.

Изменение нормальной составляющей скорости при ударе происходит согласно формуле

откуда

$$
k=\left|\frac{u_{n}}{V_{n}}\right| \text {, }
$$

$$
\left|u_{n}\right|=k\left|V_{n}\right|
$$

где $\left|u_{n}\right|$ и $\left|V_{n}\right|$ - абсолютные значения проекций скоростей $\vec{u}$ и $\vec{V}$ на нормаль.

Модуль скорости центра шара $u$ после удара

$$
u=\sqrt{u_{\tau}^{2}+u_{n}^{2}}=\sqrt{\frac{V_{\tau}^{2}}{f_{3}^{2}}+k^{2} V_{n}^{2}}=\sqrt{\frac{(V \sin \beta)^{2}}{f_{3}^{2}}+(k V \cos \beta)^{2}}=V \sqrt{\frac{\sin ^{2} \beta}{f_{3}^{2}}+k^{2} \cos ^{2} \beta} .
$$

Так как $\beta+\varphi=90^{\circ}$, то уравнение 21 примет вид

$$
u=V \sqrt{\frac{\sin ^{2}(90-\varphi)}{f_{3}^{2}}+k^{2} \cos ^{2}(90-\varphi)} .
$$

Находим связь между углом падения частицы $\beta$ и углом отражения $\delta$ :

$$
\begin{gathered}
\operatorname{tg} \beta=\frac{V_{\tau}}{\left|V_{n}\right|} ; \\
\operatorname{tg} \delta=\frac{u_{\tau}}{\left|u_{n}\right|}=\frac{V_{\tau}}{k\left|V_{n}\right|}=\frac{1}{k} \operatorname{tg} \beta .
\end{gathered}
$$

Так как $k<1$, то

$$
\operatorname{tg} \delta>\operatorname{tg}(90-\varphi) \text { и } \delta>(90-\varphi),
$$

т. е. угол отражения больше угла падения.

Результаты исследования. Полученные аналитические описания процесса движения частицы по диску и его сходу с него при различных условиях получены лишь как отдельные частные решения, и применение их к реальным процессам может быть реализовано только при компьютерных расчетах численных моделей. Исходя из анализа предложенных на сегодняшний день методов решений подобных задач, определено, что для нашего случая наиболее эффективным является использование системы программного комплекса Mathcad.

Расчет производился при следующих условиях. Радиус подачи частицы на лопатку $r_{o}$ выбран в пределах 0,04...0,1, исходя из конструктивных особенностей диска (диск радиусом 0,12 м с втулкой 0,4 м). Частота вращения диска $\omega-900$ об/мин, масса семени $0,009 \cdot 10^{-3}$ кг, коэф- 
фициенты трения частицы о диск и о лопатку $f_{1}$ и $f_{2}-0,04$; скорость воздушного потока, образованного вентилятором системы очистки $v_{g}$, $0,1 \mathrm{~m} / \mathrm{c}$.

График изменения величины скорости схода семян с диска при различном значении места подачи частицы на диск приведен на рисунке 6, где по оси х величина характеризует место подачи частиц на диск, а по оси у величина характеризует скорость схода семян с диска.

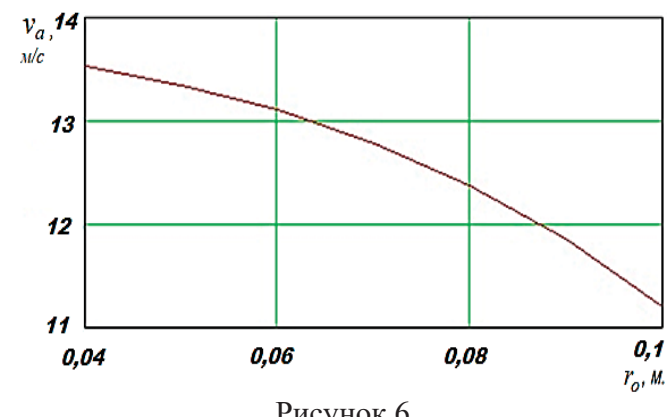

Рисунок 6

График зависимости скорости схода частицы с диска от места подачи

Из рисунка 6 видно, что зона попадания на диск от радиуса $0,04 \ldots 0,08$ м характеризуется наивысшей скоростью схода частиц, попадаемых в эту зону $(12,4 \ldots 13,5$ м/с). Далее скорость частиц уменьшается по мере попадания частиц ближе к кромке диска. Отсюда рекомендуемая зона подачи на диск $-0,04 \ldots 0,08$ м.

График позволяет в соответствии со схемой технологического процесса скарификации семян определить технологические параметры, влияющие на характер движения семян по диску в первой зоне (зона скарификации) и выходные параметры: место подачи семян на диск, скорость схода семян с диска.

В дальнейшем проведено моделирование движения семени с момента схода с диска до соприкосновения диска с абразивной поверхностью скарификатора с использованием уравнений 18-22, позволяющих спрогнозировать при заданных параметрах (скорость частицы, угол наклона плоскости, зернистость абразива) кинематические характеристики как производные координат по времени, а также представить ее движение в графическом виде. Вследствие малого зазора между кромкой диска и абразивным кругом $(0,0032$ м) скорость схода семян принята за начальную скорость удара частицы об абразив.

Моделирование произведено в программе «Абразив», написанной на языке программирования Delphi в интегрированной среде Dev-C++, разработки приложений для языков программирования $\mathrm{C} / \mathrm{C}++$ (рисунок 7 ).

По результатам моделирования установлены (рисунок 8) зависимость угла отражения семени от абразивной поверхности при различных скоростях удара $-10 \ldots 18$ м/с (зона подачи на диск - 0,06 м, масса семени $0,009 \cdot 10^{-3}$ кг, коэффициент трения частицы о поверхность 0,06; скорость воздушного потока, образованного вентилятором системы очистки $-0,1 \mathrm{~m} / \mathrm{c}$, зернистость абразива - 50, угол наклона абразивной поверхности $45^{\circ}$ ).

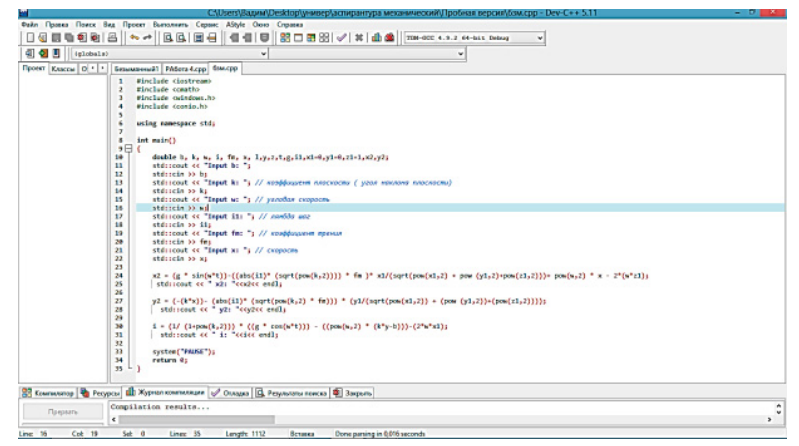

Рисунок 7

Код программы «Абразив»

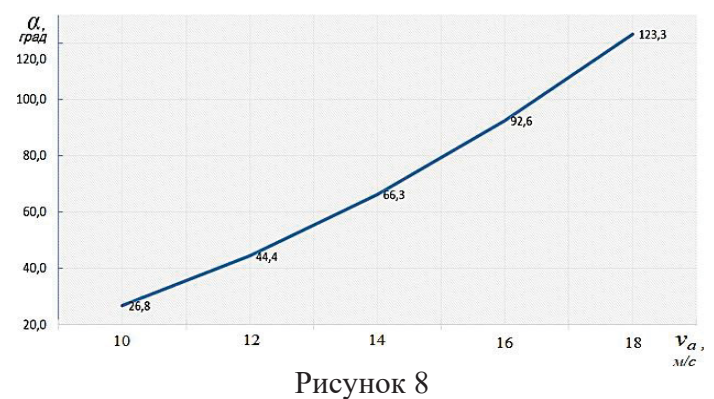

График зависимости угла отражения семени от начальной скорости соприкосновения с абразивной поверхностью, расположенной под углом 45 град к диску

Отмечено, что при скорости удара выше $13 \mathrm{~m} / \mathrm{c}$ происходит упругий удар семени и угол отражения составляет 45 и более градусов. При меньших значениях скорости удара угол отражения семени от абразивной поверхности составляет менее 45 град, то есть семя под действием силы Кориолиса прижимается, скользит, получает царапину и сходит с поверхности абразива.

Таким образом, математическая модель и расчет ее в программе «Абразив» моделируют два варианта скарификации: при ударе о абразивную поверхность и при скольжении по ней.

Таким образом, на основании общих законов механики относительного движения получены уравнения, позволяющие в соответствии со структурной схемой обработки семян (рисунок 2) определить конструктивные и технологические параметры, влияющие на процесс скарификации в первой зоне: скорость и угол соприкосновения семян с абразивной поверхностью, угол и скорость отражения семян от поверхности, что позволяет спрогнозировать выходные показатели качества обработки - степень скарификации и степень дробления семян.

Выводы. Предложена технология и техническое решение, обеспечивающее повышение качества скарификации при трех последовательно выполняющихся механизированных операций: ска- 
рификации, очистки семян и обработки их микробиологическим препаратом ризоторфин.

Проведены теоретические исследования технологического процесса скарификации семян методами классической механики и современными пакетами прикладных компьютерных программ, позволившие обосновать технические параметры и режимы работы устройства. Определено, что зона попадания на диск от радиуса 0,04...0,08 м характеризуется наивысшей скоростью схода частиц, попадаемых в эту зону $(12,4 \ldots 13,5$ м/с). Далее скорость частиц уменьшается по мере попадания частиц ближе к кромке диска. Отсюда рекомендуемая зона подачи на диск $-0,04 \ldots 0,08$ м.

Установлено, что при скорости удара выше 13 м/с происходит упругий удар семени и угол отражения составляет 45 и более градусов. При меньших значениях скорости удара угол отражения семени от абразивной поверхности составляет менее 45 град, то есть семя под действием силы Кориолиса прижимается, скользит, получает царапину и сходит с поверхности абразива. Это позволяет смоделировать два варианта скарификации: при ударе о абразивную поверхность и при скольжении по ней.

\section{Библиографический список}

1. Хасанов, Э.Р. Перспективные направления совершенствования способов и конструкции машин для инкрустации семян защитностимулирующими препаратами [Текст]: рекомендации / Э.Р. Хасанов, Р.Р. Камалетдинов, Д.Ю. Широков. Уфа: Башкирский ГАУ, 2012. $30 \mathrm{c}$.

2. Дринча, В.М. Инокуляция семян бобовых культур [Текст] / В.М. Дринча, Е.И. Кубеев // Аграрный эксперт. 2009. № 5. С. 37.

3. Камалетдинов, Р.Р. Особенности машин для обработки сельскохозяйственных культур биопрепаратами [Текст] / Р.Р. Камалетдинов, Э.Р. Хасанов, Р.М. Хайруллин, Р.Х. Сираев, Т.С. Минина // Механизация и электрификация сельского хозяйства. 2007. № 6. С. 2-3.

4. Кузнецов, И.Ю. Козлятник восточный как фактор агрономического успеха [Текст] / И.Ю. Кузнецов, С.Н. Надежкин // Вестник Башкирского государственного аграрного университета. 2005. № 6. С. 14-16.

5. Мокиев, В.Ю. Обоснование конструктивно-технологической схемы и основных параметров вытирающе-скарифицирующего устройства семян трав [Текст]: дис. ... канд. техн. наук / В.Ю. Мокиев. Киров: Зональный научно-исследовательский институт сельского хозяйства Северо-Востока имени Н.В. Рудницкого, 2017.

6. Ахламов, Ю.Д. Машины для семеноводства трав [Текст] / Ю.Д. Ахламов, И.М. Гринчук, В.К. Журкин. М.: Машиностроение, 1968. 172 с.

7. Хасанов, Э.Р. Обоснование показателей качества работы скарификатора семян козлятника [Текст] / Э.Р. Хасанов, Д.И. Маскулов, Р.З. Мусин // Вестник Башкирского государственного аграрного университета. 2019. № 3 (51). С. 114-120. DOI: 10.31563/1684-7628-2019-51-3-114-120.

8. Вербовский, А.В. Обоснование параметров и режимов работы дискового скарификатора для предпосевной обработки семян многолетних бобовых культур [Текст]: дис. ... канд. техн. наук / А.В. Вербовский. Новосибирск: Сибирский научно-исследовательский институт механизации и электрификации сельского хозяйства
Сибирского отделения Российской академии сельскохозяйственных наук, 2009.

9. Хасанов, Э.Р. Пути повышения качества обработки семян с минимальным травмированием [Текст] / Э.Р. Хасанов, М.Х. Байгускаров, М.Р. Биктимиров // Достижения науки - агропромышленному производству. Материалы XLVIII международной научно-практической конференции. Челябинск: ЧГАУ, 2009. Ч. IV. C. 260-263.

10. Хасанов, Э.Р. Разработка операционной технологии предпосевной обработки семян козлятника экспериментальным скарификатором [Текст] / Э.Р. Хасанов, Р.Р. Камалетдинов, Д.И. Маскулов, Р.3. Мусин // Вестник Башкирского государственного аграрного университета. 2020. № 1 (53). C. 142-148. DOI: 10.31563/ 1684-7628-2020-53-1-142-148.

11. Припоров, Е.В. Центробежный аппарат с подачей материала вдоль лопаток [Текст] / Е.В. Припоров, С.Н. Картохин // Научный журнал Кубанского государственного аграрного университета. 2015. № 112 (08). С. 86-94.

12. Бурков, А.И. Результаты агротехнической оценки качества работы клеверотерки-скарификатора КС-0,2 [Текст] / А.И. Бурков, М.В. Симонов, В.Ю. Мокиев // Аграрная наука Евро-Северо-Востока. 2015. № 4 (47). С. 76-80.

13. Черноволов, В.А. Моделирование процессов распределения минеральных удобрений центробежными аппаратами [Текст] / B.А. Черноволов, Т.М. Ужахов. Зерноград: Азово-Черноморский государственная агроинженерная академия, 2010. 269 с.

14. Василенко, П.М. Теория движения частицы по шероховатым поверхностям сельскохозяйственных машин [Текст] / П.М. Василенко. Киев: Украинская АСХН, 1960. 283 с.

15. Симонов, М.В. Повышение эффективности послеуборочной обработки семян трав совершенствованием технологического процесса и рабочих органов клеверотерок [Текст]: дис. ... докт. техн. наук / М.В. Симонов. Киров: ФГБНУ ФАНЦ Северо-Востока, 2020. 


\section{Сведения об авторах}

1. Хасанов Эдуард Рифович, доктор технических наук, профессор кафедры сельскохозяйственных и технологических машин, ФГБОУ ВО Башкирский ГАУ, г. Уфа, ул. 50-летия Октября, 34, тел.: +7 (347) 228-08-71, e-mail: hasan_ed@mail.ru.

2. Каримов Хасан Талхиевич, кандидат технических наук, старший преподаватель кафедры механики и конструирования машин, ФГБОУ ВО Башкирский ГАУ, г. Уфа, ул. 50-летия Октября, 34, тел.: +7 (347) 228-08-71, e-mail: carimov.ces@mail.ru.

3. Маскулов Дамир Ильшатович, аспирант кафедры сельскохозяйственных и технологических машин, ФГБОУ ВО Башкирский ГАУ, г. Уфа, Ул. 50-летия Октября, 34, тел.: +7 (347) 228-08-71, e-mail: dmaskulov@mail.ru.

Для исследований предложена конструкция экспериментального скарификатора, позволяющего механизированным способом выполнять три последовательные операции по предпосевной обработке семян: скарификацию семян; очистку скарифицированных семян от образовавшейся при обработке пыли и примесей от абразивной поверхности шлифовального круга; обработку очищенных семян микробиологическим препаратом «Ризоторфин». Каждая операция происходит в своей зоне обработки семян скарификатора. Проведенные теоретические исследования технологического процесса скарификации семян методами классической механики и современными пакетами прикладных компьютерных программ позволяют обосновать технические параметры и режимы работы устройства. Опреде- лено, что зона попадания на диск от радиуса 0,04...0,08 м характеризуется наивысшей скоростью схода частиц, попадаемых в эту зону $(12,4 \ldots 13,5$ м/с). Далее скорость частиц уменьшается по мере попадания частиц ближе к кромке диска. Отсюда рекомендуемая зона подачи на диск - 0,04...0,08 м. Установлено, что при скорости удара выше $13 \mathrm{~m} / \mathrm{c}$ происходит упругий удар семени, и угол отражения составляет 45 и более градусов. При меньших значениях скорости удара угол отражения семени от абразивной поверхности составляет менее 45 град, то есть семя под действием силы Кориолиса прижимается, скользит, получает царапину и сходит с поверхности абразива. Это позволяет смоделировать два варианта скарификации: при ударе о абразивную поверхность и при скольжении по ней.

\section{E. Khasanov, Kh. Karimov, D. Maskulov}

\section{THEORETICAL STUDIES OF SCARIFICATION OF EASTERN GALEGA SEEDS WITH AN EXPERIMENTAL SCARIFICATOR}

Key words: scarification; seed scarifier; rotating disc; particle; impact speed; descent speed; angle of reflection; abrasive.

\section{Authors' personal details}

1. Eduard Khasanov, Doctor of technical sciences, professor of the Department of agricultural and technological machines, Federal State Budgetary Educational Institution of Higher Education «Bashkir State Agrarian University», Ufa, 50-letiya Octyabrya st., 34, e-mail: hasan_ed@mail.ru.

2. Khasan Karimov, Candidate of technical sciences, associate professor of the Department of agricultural and technological machines, Federal State Budgetary Educational Institution of Higher Education «Bashkir State Agrarian University», Ufa, 50-letiya Octyabrya st., 34, e-mail: carimov.ces@mail.ru.

3. Damir Maskulov, Post-graduate of the Department of agricultural and technological machines, Federal State Budgetary Educational Institution of Higher Education «Bashkir State Agrarian University», Ufa, 50-letiya Octyabrya st., 34, e-mail: dmaskulov@mail.ru.

For research, the design of an experimental scarifier is proposed, which allows performing three sequential operations for the pre-sowing treatment of seeds in a mechanized way: scarification of seeds; cleaning scarified seeds from the dust and impurities formed during processing from the abrasive surface of the grinding wheel; treatment of the treated seeds with the microbiological preparation «Rizotorfin». Each operation takes place in its seed treatment zone of the scarifier. The carried out the- oretical studies of the technological process of seed scarification using classical mechanics, and modern packages of applied computer programs make it possible to substantiate the device's technical parameters and operating modes. It has been determined that the zone which hits the disk from the radius of $0,04 \ldots 0,08 \mathrm{~m}$ is characterized by the highest rate of descent of particles falling into this zone $(12,4 \ldots 13,5 \mathrm{~m} / \mathrm{s})$. Further, the particle velocity decreases as the particles get closer to the edge of the 
disk. Hence, the recommended feed zone to the disk is $0,04 \ldots 0,08 \mathrm{~m}$. It has been established that at an impact speed above $13 \mathrm{~m} / \mathrm{s}$, an elastic impact of the seed occurs, and the reflection angle is 45 degrees or more. At lower values of the impact speed, the angle of reflection of the seed from the abrasive sur-

(C) Хасанов Э.Р., Каримов Х.Т., Маскулов Д.И. face is less than 45 degrees; that is, the seed under the Coriolis force's action is pressed, slides, gets a scratch, and comes off the abrasive surface. It makes it possible to simulate two variants of scarification: when hitting an abrasive surface and when sliding on it.

УДК 628.987

DOI: 10.31563/1684-7628-2020-56-4-144-150

С.К. Шерьязов, И.И. Каримов, С.А. Попова, Г.Р. Каримова

\section{УПРАВЛЕНИЕ РЕЖИМОМ ДОСВЕЧИВАНИЯ ТЕПЛИЧНЫХ РАСТЕНИЙ}

\section{Ключевые слова: тепличные растения; досвечивание; LED-облучатели; спектр излучения; геометрия стебля; управление досвечиванием.}

Введение. Для тепличных растений важно поддерживать необходимый процесс фотосинтеза, и в условиях недостаточного солнечного излучения требуется досвечивание. Основным источником досвечивания в современных теплицах пока остаются натриевые лампы, которые ограничивают управление процессом досвечивания $[1,2]$. В теплицах осуществляют досвечивание растений на протяжении 20 часов, что оказалось не совсем оправданным с точки зрения биологического процесса и экономики. Так, эксперименты по изучению роста растений огурца показали резкое снижение процесса фотосинтеза после нескольких часов интенсивного досвечивания [3, 4]. Следовательно, требуется обоснование режима досвечивания и оптимизация параметров используемых современных облучателей, позволяющих управлять процессом. В настоящее время наметилась тенденция использования более современных и экономичных источников света LED (светодиодных)-облучателей. Они уже пришли в промышленные теплицы и преобразуют электроэнергию в определенный спектр излучения - тот, который нужен растениям больше всего $[5,6]$. Однако эксперименты c LED-облучателями пока находятся на начальном этапе, и пока незначительное количество культур прошли через стадию первичных исследований. Традиционные тепличные овощные растения со сроком вегетации до 10-12 месяцев в этом плане пока еще мало изучены и в литературных источниках информация по этому вопросу появляется очень редко [7, 8, 9].

В процессе выращивания тепличных растений важно управлять процессом досвечивания. Процесс облучения предполагает досвечивание растений заданным спектром и мощностью излучения. Исследование влияния красно-синего спектра излучения LED в процессе досвечивания растений выявило некоторые закономерности. Максимальным фотосинтез возможен только при оптимальном сочетании в процентном соотношении синего и красного спектров при обязательном наличии излучения ламп широкого солнечного спектра $[10,11,12]$.

Спектры излучения в процессе облучения по-разному влияют на геометрию выращиваемого тепличных растений. Так необоснованное досвечивание заданными спектрами излучения может сильно вытянуть стебель растения, или растение может затормозить свой рост. Тогда появляется необходимость управлять параметрами излучения по заданному алгоритму. Для этого требуется разработка математической модели, связывающая параметры излучения с показателями роста растений. Например, сюда можно отнести модели регрессионного типа [13], и они способны количественно оценить влияние различных сочетаний факторов среды обитания на жизнедеятельность растений без глубокого анализа биологических процессов, протекающих в них. Факторы, влияющие на жизнедеятельность растений, но не вошедшие в эксперимент, номинально присутствуют в нем в качестве усредненных параметров среды обитания без возможности их варьирования. В этом случае эксперимент будет признан корректным, а результаты исследования, вычисленные по модели, могут быть использованы для регулирования условий содержаний растений в теплицах $[14,15]$. В настоящее время нет какой-либо рекомендации по досвечиванию тепличных растений, выполнение которых позволило бы выращивать здоровые растения при оптимальном фотосинтезе с минимальными затратами на электрическую энергию [16]. Тогда актуальными являются изучение влияния спектров излучения на жизнедеятельность растений и умение управлять ими для минимизации необходимых затрат на производство тепличной продукции.

Цель и задачи исследования. Для изучения процессов влияния спектрального состава LED- 